\title{
O sentido heroico da vida em Vidas Novas, de Luandino Vieira
}

Daniel Laks ${ }^{a}$

\begin{abstract}
Resumo
O herói e sua aventura talvez constitua um dos tópicos mais explorados ao longo da história da narrativa, remontando à antiguidade clássica. A partir das diferentes figurações do herói podemos perceber aspectos específicos das sociedades que os produziram. Como entendiam o tempo histórico, como definiam os conceitos de justiça, valor ou como representavam conflitos. O mito do herói se pretende como narrativa exemplar, revelando a moral de determinada comunidade e conferindo origem, valor e propósito para os mais diversos elementos culturais. Nesse sentido, a partir do mito do herói é possivel perceber as influências do campo político nos domínios da cultura. Mais ainda, os heróis instituem novas comunidades, fundam cidades e novas formas de habitar o espaço. Suas estórias alteram a maneira de entender a experiência do presente e as expectativas para o futuro, revelando as influências do campo da experiência estética na produção de formas lógicas. O objetivo desse artigo é comparar alguns dos principais aspectos do mito do herói em sua tipologia clássica com as figurações do herói em Vidas Novas, de Luandino Vieira. A partir das possiveis aproximações e afastamentos, o artigo pretende discutir como diferentes maneiras de compreender a existência no mundo emergem para a superficie da linguagem e para as formas narrativas.
\end{abstract}

Palavras-chave: Herói; Autoconsciência histórica; Luandino Vieira; Vidas Novas; Realismo.

Recebido em 23 de janeiro de 2017 Aceito em 13 de julho de 2017

${ }^{a}$ Doutor pela PUC-Rio com sanduíche na Universidade de Coimbra (2016). Pós-doutorando no Núcleo de Estudos Portugueses e Africanos (NEPA) da UFF. E-mail: daniellaks@yahoo.com 
Heróis individuais e causas coletivas são elementos temáticos frequentemente revisitados ao longo da história da narrativa e comumente associados a uma dimensão épica da escrita. A figura do herói, a grandiosidade de sua causa para o coletivo e a maneira como a aventura se desenrola são elementos que podem ser encontrados em narrativas produzidas durante os mais variados momentos históricos, abrindo janelas para percebermos aspectos específicos das culturas nas quais essas estórias foram produzidas. A partir das diferentes tipificações do mito do herói, somos capazes de vislumbrar a relação entre indivíduos de uma determinada época com o mundo natural e com representações de divindades. Heróis expressam também a dimensão moral de uma determinada comunidade, suas estórias fornecem os modelos a serem seguidos e avisam sobre os perigos e as consequências dos desvios de conduta. Suas aventuras revelam traços de como diferentes sociedades entendiam o cosmos, como expressavam virtude, beleza ou conflito. Figurações variadas do mito do herói remetem a experiências específicas de percepção do tempo e do espaço que emergem para a forma narrativa e para a própria superfície das palavras, alterando seus significados. Heróis fundam novas tradições, iniciam novos tempos.

Os oito contos que compõem o livro Vidas Novas são narrativas de caráter realista, produzidas entre junho e julho de 1962 dentro do Pavilhão Prisional da PIDE, em Luanda, nos contextos iniciais da guerra pela independência de Angola. A estratégia realista de escrita em Luandino Vieira visava a uma agenda política específica: a conscientização sobre as condições às quais os indivíduos angolanos eram submetidos durante a ditadura salazarista para que mais pessoas, a partir dessa percepção, pudessem aderir à causa revolucionária. São narrativas que se pretendiam como mais do que simples entretenimento: buscavam trazer um peso a eventos específicos, não apenas narrando de forma distanciada as relações entre os diferentes personagens, mas apresentando uma posição particular como única alternativa justa. Essa política de escrita remete à noção de mito, não como estórias fantasiosas, mas como narrativas que definem o mundo, que produzem sentido e significado para além de si mesmas. Estórias que oferecem explicações para elementos culturais, dotando-os de origem, valor e propósito. 
O objetivo desse artigo é analisar a estratégia de escrita de Luandino Vieira em Vidas Novas a partir das aproximações e afastamentos entre os personagens principais dos contos e os diferentes tipos de heróis da tradição clássica. Se possíveis aproximações entre os personagens de Vidas Novas e os padrões do mito do herói remetem a aspectos que parecem transcender a vida de um único indivíduo, contendo lições sobre a existência humana para além do seu tempo e espaço, os possíveis afastamentos parecem revelar especificidades das experiências históricas nos diferentes contextos psicossociais. Mais ainda, o artigo visa a investigar como as características da jornada do herói nas narrativas de Luandino Vieira parecem apresentar uma autoconsciência histórica específica da modernidade que, em conexão com a tradição realista de escrita, seculariza elementos tradicionais da narrativa mítica.

Os heróis clássicos são personagens provenientes da tradição oral grega, como Hércules, por exemplo, um dos principais modelos de herói ocidental, ou descritos em poemas épicos gregos, como a Ilíada e a Odisseia ou romano como a Eneida. Joseph Campbell (1997), em O herói de mil faces descreve a estrutura padrão do mito do herói a partir do que ele define como o esquema do monomito: "o percurso padrão da aventura mitológica do herói é uma magnificação da fórmula representada nos rituais de passagem: separação-iniciaçãoretorno - que podem ser considerados a unidade nuclear do monomito" (CAMPBELL, 1997, p. 14). A trajetória do herói, dessa maneira, começa com uma separação voluntária ou forçosa do seu mundo conhecido. A partir desta separação, o herói entra em contato com um mundo novo onde se processará uma experiência iniciática. Por fim, o indivíduo sobrevive a iniciação, mas é transformado por ela e retorna mais sábio para o seu mundo antigo. "O herói retorna de sua misteriosa aventura com o poder de trazer benefícios aos seus semelhantes"1.

Os mitos clássicos obedecem também a uma lógica de hierarquização das vidas: tratam das aventuras de semideuses, reis/mandatários ou pessoas com habilidades especiais. Em outras palavras, os mitos clássicos não abordam a vida de pessoas comuns, mas de indivíduos que seriam capazes de despertar a atenção dos Deuses. Assim nos surgem as narrativas de Hércules, filho de Zeus, Ulisses, rei de Ítaca e Eneias, filho da Deusa Vênus. Heróis descritos a partir de 
suas características extraordinárias. Mesmo antes de adentrar a jornada iniciática que preparará o herói para aceitar o seu destino, aquele indivíduo já se encontra caracterizado como portador de habilidades sobre-humanas ou de um senso extremamente avançado de engenhosidade: O herói "já vem ao mundo com duas 'virtudes' inerentes à condição e natureza: a timé, a 'honorabilidade pessoal' e a areté, a 'excelência', a superioridade em relação a outros mortais" (BRANDÃO, 2002, p. 23). Nesse sentido, as características fundamentais do herói clássico estão muito mais relacionadas à sua genealogia e capacidades físicas ou intelectuais do que ao ato de abrir mão do seu bem pessoal em prol do bem comum.

A condição sobre-humana congênita ao herói desperta a simpatia de algumas deidades e a antipatia de outras. A epopeia se constrói como um embate entre um indivíduo ou grupo, apoiados por um ou mais deuses, contra a fúria de outras divindades que querem impedir o encontro entre o(s) herói(s) e seu(s) destino(s). Essa relação de apadrinhamento com deidades específicas possibilita, muitas vezes, o acesso do herói a dons divinatórios ou profecias de oráculos que o advertem sobre possíveis perigos e sobre o futuro glorioso a ser conquistado. O percurso em busca de si mesmo é sempre árduo e, por isso mesmo, é frequentemente facultado ao herói a oportunidade de escolher entre uma vida longa e calma ou uma vida curta e cheia de aventuras, cujos feitos ecoarão através do tempo e do espaço.

A jornada do herói é fundamentalmente uma jornada pessoal, na qual ele deve, ao fim e ao cabo, afirmar a sua identidade. Esse encontro do herói consigo mesmo é mediado por uma série de tarefas que devem ser cumpridas a fim de preparar o indivíduo para aceitar o seu grande destino. A tarefa derradeira é geralmente associada à experiência da morte como coroação do ciclo iniciático. Primeiro, uma espécie de flerte com a morte que se apresenta de forma figurativa. São exemplos dessa experiência de ultrapassagem dos limites entre o físico e o transcendente os mitos de Hércules e Eneias, que desceram ao mundo dos mortos e retornaram ao mundo natural. Esta transposição entre os limites da vida e da morte conferiu aos heróis um sentido inicial de completude. Hércules decapitou o Cérbero, cão guardião do Hades e ofereceu suas cabeças a Euristeu, rei de Miscenas, que aterrorizado com a proeza 
do herói decidiu reconhecer como completos os seus Doze Trabalhos, libertando o herói de seus serviços. Eneias, por sua vez, encontrou o seu pai, Anquises, que lhe explicou o plano da criação e o instruiu sobre o seu futuro e dos seus descendentes. A descida e retorno do Hades representam o supremo rito iniciático: "a catábase, a morte simbólica, é a condição indispensável para uma anábase, uma 'subida', uma escalada definitiva na busca da anagnórisis, do autoconhecimento, da transformação do que resta do homem velho no homem novo" (BRANDÃO, 2002, p. 114).

A morte simbólica é também metaforizada através da imagem da experiência do ventre da baleia. O ventre da baleia representa um lugar escuro e úmido, que pode assemelhar-se a um útero ou um túmulo, remetendo à tensão entre vida e morte, à separação entre o mundo físico e o mundo que existe para além desse. Ficar preso no ventre da baleia é estar segregado num espaço de privação que permite ao herói dar-se conta de suas próprias limitações e, finalmente, aceitar o seu propósito: é nesse espaço que o herói pode apreender suas dores que ultrapassam as dores físicas, pode constatar suas fragilidades e, finalmente, refletir sobre os efeitos de seus erros em vidas alheias. $\mathrm{O}$ ventre da baleia representa a barreira que o herói deve transpor para poder renascer para o mundo físico. Não propriamente um mundo para além do mundo dos vivos, mas um mundo interno, uma jornada para as profundezas do ser. Até que a transposição da barreira que separa os dois esteja completa, é como se o herói habitasse o domínio dos mortos:

A ideia de que a passagem do limiar mágico é uma passagem para uma esfera de renascimento é simbolizada na imagem mundial do útero, ou ventre da baleia. O herói, em lugar de conquistar ou aplacar a forca do limiar, é jogado no desconhecido, dando a impressão de que morreu. (CAMPBELL, 2007, p. 91)

A morte simbólica como coroação da jornada de iniciação antecipa um aspecto incontornável na narrativa heroica: para habitar a esfera do mito é necessário que a narrativa possa ultrapassar a duração de uma vida. O herói deve morrer para que seus feitos possam ecoar para além de seu tempo. A morte física, nesse sentido, funciona como a etapa final da trajetória, onde o herói deve transcender o seu corpo carnal para assumir o seu lugar na eternidade: "A morte do herói, todavia, se 
constitui no clímax de sua dokimasía, do conjunto de provas por que passou esse espancador de trevas. A morte é seu último grau iniciático" (BRANDÃO, 2002, p. 64). O mito de Hércules, exemplo padrão desse tipo de construção narrativa, pode ser, assim, dividido em quatro etapas: o nascimento/infância; o ciclo dos Doze Trabalhos; aventuras posteriores e o ciclo da morte que consagra a ascensão do herói. "Só o aniquilamento do Hércules humano permitiu a apoteose do filho de Zeus" (BRANDÃO, 2002, p. 131).

É a partir da morte do herói que se fundam também as bases para a relação entre heroísmo e sentimento pátrio, entre os feitos do indivíduo e sua representatividade para uma comunidade específica. O mito do herói está muitas vezes associado à proteção de uma cidade ou mesmo com a instituição de novas formas de habitar o espaço de uma determinada comunidade. Depois de morto, o herói passa a ocupar um lugar intermediário entre os homens e os deuses, transformando-se em patrono de cidades para protegê-las contra invasões e doenças, além de estabelecer comportamentos sociais, políticos e ritualísticos particulares:

São ancestrais de raças, povos e famílias importantes, (...). Eméritos fundadores de cidades e colônias inventam e revelam muitas instituições humanas, como as leis que governam a cidade, as normas da vida urbana, a monogamia, a metalurgia, a escrita, o canto, a tática militar. Instituem jogos esportivos; participam ativamente de guerras, da mântica, da iátrica e dos mistérios. E mais do que tudo, em cometimentos gigantescos, varrem da terra os bandidos, as feras e os monstros... (BRANDÃO, 2002, p. 53).

Se os heróis da mitologia grega já antecipavam uma relação com o senso de comunidade, os heróis da mitologia romana exacerbam ainda mais essa relação, fundando uma ideia de nacionalidade que emana da narrativa mítica. Os principais heróis romanos estão intimamente ligados à fundação ou à manutenção da glória de Roma. O Império Romano absorveu os mitos gregos relacionados a criação. Dessa forma, os mitos romanos se desenvolveram focando seus interesses em questões relacionadas especificamente a Roma. Roma era o centro ao redor do qual orbitavam todas as narrativas que deviam ser contadas.O movimento de apropriação da épica grega dirige o sentido final da narrativa 
para o futuro. A Ilíada descreve as batalhas de indivíduos que combatem por suas instituições, mas que prezam pela glória pessoal, pela bravura, por questões individuais e por seu destino pessoal. "O coletivo era visto em segundo plano no épico homérico e o futuro não era uma preocupação como na Eneida" (RODRIGUES, 2005, p. 11). Em sua narrativa, Virgílio atribuiu às palavras do próprio Júpiter a expressão da vontade de que Roma fosse fundada. Assim, o império era representado como desígnio da providência, reverberando pela genealogia de Eneias até desaguar em Rômulo, herói fundador que empresta o seu nome a polis:

[Júpiter:] [...] Rômulo, alimentado pelo sangue da loba, dará continuidade a raça de Enéias, fundará a cidade de Marte e nomeará os romanos com seu nome. Eu não lhes dei limite de tempo ou poder: dei-lhes um império sem fim. Ainda mais: até mesmo Juno, que os castiga através da raiva o mar, a terra e o céu, mudará para sentimentos melhores para com eles e os protegerão como eu, o povo de toga, os romanos mestres do mundo. Esta é minha vontade (VIRGÍLIO, 2005, p. 272-280).

A descendência heroica, que é também parte divina, para além de justificar a fundação de Roma como império eterno e indispensável para a manutenção da paz, era utilizada para validar o exercício do poder por dinastias de mandatários que reivindicavam essa origem. Virgílio, que viveu sob o governo de Augusto, revelava uma estratégia deliberada de escrita ao ligar a linhagem do governante à linhagem de Eneias e Rômulo, conferindo um estatuto especial não apenas para Augusto, mas para todos os seus possíveis descendentes. Salientando as conquistas territoriais de César, Virgílio ligava a gênese da casa Juliae ao filho de Eneias, Iulo: "A vitória de César sobre a Grécia se torna o ápice do mito de Tróia, pois a cidade que antes foi destruída pelos gregos agora os dominava: o ciclo da vingança estava completo" (PIRES, 2013, p. 139). A hegemonia romana tinha assim a sua personificação em César e na gens Juliae, família que garantiria a paz eterna no mundo:

[Júpiter:] Um dia, nos anos que se seguirão, a casa de Assáraco conseguirá subjugar a Ftia e a famosa Micenas e dominará Argos vencida. Desta bela raça nascerá o troiano César que estenderá o império ao Oceano e que a fama elevará aos astros: seu nome vem do grande Iulo. Um dia, ele chegará carregado de espólios do Oriente, tu o receberás no 
céu em toda tranquilidade e os homens também se dirigirão a ele em preces. Então, deposta a guerra, se findará a idade do ferro (VIRGílIO, 2005, p. 283-290).

O processo de transição da figura do herói clássico para o herói moderno conservou algumas das principais características do mitologema original, transformando-as, entretanto, de acordo com uma perspectiva de desencantamento do mundo, condição própria da modernidade para as relações entre o discurso filosófico e o discurso estético. Milan Kundera (2009), em A arte do romance, propõe que as relações entre a experiência estética e a experiência política nos tempos modernos estão submetidas a um paradoxo, que pode ser representado na tensão entre Descartes e Cervantes. Os pensamentos filosófico e científico, que elevaram o homem a senhor e dono da natureza, continham em si, também, o germe de sua ruína. As questões intrínsecas ao homem, paulatinamente, foram sendo suplantadas em importância pelos domínios da técnica, da política e da história que o possuíam, consumiam-no e o ultrapassavam. A tradição do romance, iniciada por Cervantes, teria surgido, assim, para preencher esse espaço de investigação sobre o mundo da vida, sobre o que é próprio do espírito humano:

Compreender com Descartes o ego pensante como fundamento de tudo, estar assim só em face do universo, é uma atitude que Hegel, a justo título, julgou heroica. Compreender com Cervantes o mundo como ambiguidade, ter de enfrentar, em vez de uma só verdade absoluta, muitas verdades relativas que se contradizem (verdades incorporadas em egos imaginários chamados personagens), ter portanto como única certeza a sabedoria da incerteza, isso não exige menos força (KUNDERA, 2009, p. 14).

Kundera defende que o romance moderno se encontra num universo onde a razão cartesiana consumia um a um os antigos valores que organizavam as formas tradicionais de vida. Mas, o momento que deveria consagrar o apogeu do racionalismo ocidental foi, no entanto, cada vez mais penetrado pelo puro irracionalismo, pela imposição da força que se estabelecia para preencher o espaço criado pela ausência de um sistema de valores amplamente admitido que pudesse lhe fazer oposição. A proposta de pensar a decomposição da verdade única e divina em centenas de verdades relativas que pudessem ser divididas entre os homens como condição 
moderna parece confluir com a análise da dissolução do topos Historia Magistra Vitae, conforme observado por Reinhart Koselleck (2006) em Futuro Passado - Contribuição à semântica dos tempos históricos.

Para Koselleck, o sentido da história como passado exemplar foi esvaziado a partir da transformação, em meados do século XVIII, do antigo conceito de história (Historie) em "história em si" (die Geschichte selbst), fundando uma nova forma de perceber-se o tempo histórico: "A nova história (Geschichte) adquiriu uma qualidade temporal própria. Diferentes tempos e períodos de experiência, passíveis de alternância, tomaram o lugar outrora reservado ao passado como exemplo" (KOSELLECK, 2006, p. 46). A história como evento único, ou um entremeado de ocorrências, não seria capaz de instruir da mesma maneira do que a história compreendida como caso exemplar. Essa transformação do conceito de história se relaciona intimamente com as possibilidades do campo estético de filiação das diferentes narrativas modernas ao domínio do seu tempo cronológico específico. As estórias produzidas passaram a afastar-se gradativamente das descrições de aventuras atemporais para transitarem nos domínios sociais, culturais e políticos de suas épocas características.

A produção literária de Luandino Vieira se inscreve no contexto das dinâmicas da segunda metade do século $\mathrm{XX}$, sob a forma de crítica da modernidade. Os egos imaginários engendrados em Vidas Novas são heróis revolucionários, que, necessariamente, desafiam o poder instituído ao qual o autor, por sua vez, encontrava-se também submetido durante o seu exercício de escrita. Isso situa a estratégia da narrativa heroica de Luandino Vieira em um plano similar à de Virgílio, mas em trajetória vetorial oposta. Enquanto a mítica de Virgílio pretendia justificar o Império Romano e a governança da casa de Juliae, as narrativas de Luandino visavam destituir o domínio colonial português sobre Angola. Dessa forma, as estórias de Luandino são estórias do contrapoder. Mais ainda, de forma análoga às aventuras de Eneias, os oito contos que compõem Vidas Novas pretendiam contribuir para a fundação de uma ideia específica de nacionalidade que deslocava o sentido da história para o tempo futuro. A justiça dos atos contrários ao poder instituído se fundava, assim, nas expectativas de um mundo que só se tornaria possível após a revolução. Assim, 
o tópico da revolução na escrita de Luandino Vieira parece secularizar as expectativas apocalípticas de salvação projetadas em um futuro totalizante. Em outras palavras, a justificação dos atos, que só se tornaria possível através de uma reavaliação do passado, é deslocada da ideia de manifestação da providência para emergir no conceito de revolução. A legitimação histórica do direito a partir do passado se desarticula, assim, para dar lugar a uma justificação permanente que se baseia na filosofia da história. O movimento revolucionário encontrava em si mesmo a legitimação para suas ações.

Os personagens principais dos oito contos de Vidas Novas, de maneira oposta à lógica do herói clássico, não são apresentados como figuras sobre-humanas, dotadas de habilidades fantásticas e aptas a grandes proezas físicas ou intelectuais. São, pelo contrário, os indivíduos que seriam considerados descartáveis, subalternizados pelas condições impostas pelo sistema de dominação vigente. São as pessoas tidas como aquelas de quem não se esperaria nada. A personagem do primeiro conto, Dina, é uma jovem angolana que teve a sua virgindade vendida para um homem branco da região aos dezesseis anos "- Quando você vai ter dezasseis anos, já sabe, minha filha! Sô Tonho te quer na cama dele" (VIEIRA, 1985, p. 18). Depois, foi forçada pela madrinha a se tornar prostituta, comercializando o seu corpo para os soldados colonialistas, os tropas, pertencentes ao mesmo exército que havia assassinado seus pais:

Quando deitava com os tropas tinha qualquer coisa dentro dela não aceitava, mesmo que nas mamas ficavam rijas e as pernas apertavam o homem que sabia, lá dentro, bem no fundo, na pele dela e na carne dela, um bicho que não conhecia, não sabia, torcia-se, mexia, refilava" (VIEIRA, 1985, p. 16).

João Matias Kangatu, personagem do conto "À espera do luar", era um jovem pescador negro que havia sido preso após uma denúncia: "Sô Kamuanhu andava-lhe perseguir, queria-lhe pôr na rua da quitanda e aproveitou mesmo esse dia na volta da pesca para chamar o carro de polícia para lhe levar" (VIEIRA, 1985, p. 31). Nela, personagem de "À sexta feira", era a esposa de um preso político: "Toda a gente ali estava de manhã cedinho, esperando com paciência a hora de receber e entregar as únicas notícias autorizadas das pessoas 
que gostavam" (VIEIRA, 1985, p. 51). Cardoso Kamukolo, personagem do quinto conto do livro era um pobre sapateiro: "Cardoso Kamukolo era um sapateiro cambuta e grosso como boa cana dos lados do Kuanza" (VIEIRA, 1985, p. 97). Essa mesma lógica também se aplica aos demais protagonistas de Vidas Novas, cada um representando uma situação específica de exclusão social e violência vivenciada pela população angolana durante o domínio português.

Os heróis de Luandino também enfrentam uma jornada iniciática, que lhes conduz ao encontro com seus destinos. São personagens que vão ligar a sua jornada pessoal ao destino coletivo da comunidade espoliada, ainda que isso os obrigue a sacrifícios ou os exponha a riscos. Os degraus dessa iniciação, entretanto, não se realizam em um mundo fantástico e atemporal desconhecido, como no caso dos heróis clássicos, mas acontecem no mundo real, no contexto político social historicamente reconhecível das tensões geopolíticas da segunda metade do século XX. Essa representação do tempo histórico na narrativa está ligada à estratégia realista empregada por Luandino Vieira. A narrativa de Luandino se apresenta, portanto, como um exemplo de efetivação artística dos realismos de cariz socialista. Margarida Losa (1989), em $O$ herói coletivo: um aspecto da estratégia romântica do romance neorrealista, apresenta uma diferenciação entre o realismo naturalista e a estratégia efetivada pelo neorrealismo português, outro exemplo do emprego da matriz realista nos contextos da resistência cultural aos fascismos do século XX:

\begin{abstract}
A estratégia do romance naturalista, que era representar a realidade a uma luz de tal modo negativa que, por reação dialética a nível da recepção, o leitor se sentisse tentado a rejeitá-la totalmente e a desejar outra coisa muito diferente. A diferença consiste em que o autor neorrealista ultrapassa, ou até frequentemente negligencia, a preocupação de retratar a realidade em si e por si, e também não se contenta em gerar no leitor reações subjetivas de revolta. Num terceiro momento, o autor neorrealista projeta no texto igualmente a própria resolução dos conflitos e contradições apontados (LOSA, 1989, p. 35).
\end{abstract}

Assim, o conceito de real se encontra projetado para o futuro. A representação não pretende obedecer a uma lógica de reflexão especular do mundo, mas sim fundar um novo mundo a partir dos abalos gerados nas formas lógicas através 
das formas simbólicas, a partir das mediações feitas pela experiência estética. A definição de real passa a estar vinculada não ao que estritamente se apresenta, mas às possibilidades que se concretizariam a partir do emprego da estratégia realista. Do mesmo modo que a jornada iniciática dos protagonistas de Vidas Novas os prepara para seu destino revolucionário, a narrativa de Luandino Vieira objetiva plantar no seu mundo contemporâneo as sementes de suas expectativas para o futuro. Analogamente à lógica do mitologema clássico, é também a experiência da morte que laureia a trajetória dos heróis em Luandino Vieira. A morte é primeiro a morte de um eu antigo que impedia a ascensão do herói de encontro ao seu destino, que, por sua vez, liga-se ao destino de toda uma comunidade. Cada herói individual é, assim, conectado a uma causa que é coletiva e que ultrapassa o indivíduo: "Podem-nos matar, não faz mal, companheiro, somos milhões na nossa terra! Nossa luta é justa!" (VIEIRA, 1985, p. 152). A morte que consagra o fim do processo de iniciação é, assim, também nas narrativas de Vidas Novas, a secularização da experiência no ventre da baleia. Esse espaço de privação que impõe uma barreira entre o herói e o mundo da vida e que permite que o herói entre em contato com o seu eu profundo não é mais representado pelas entranhas de um monstro mágico ou o labirinto do mundo dos mortos, mas pelo espaço da violência dos agentes do Estado: "Então, em cima dos seus olhos, uma noite mais negra que a noite que corria lhe tapou nas estrelas e o cassetete arrancou-lhe para longe, para o tempo onde nada lembra" (VIEIRA, 1985, p. 23).

Alguns dos egos imaginários figurados em Vidas Novas passam apenas pela morte como metáfora do processo de tomada de consciência revolucionária. São narrativas que nos apresentam a jornada do herói apenas até o momento da iluminação pessoal. Dina, do conto homônimo, que no carro de polícia decide romper com o seu passado: “O polícia ao lado do chofer, sem mesmo se mexer, falou só: <<-Tá xalada, a gaja!〉> E estava. Xalada e feliz dessa coisa nova a disparar dentro dela" (VIEIRA, 1985, p. 24); Mário João, de “O exemplo de Job Hamukuaja", que coloca em risco sua integridade física para defender o companheiro das agressões da PIDE: "Mário João saltou para defender o amigo, insultando, nem sabia mesmo o que sucedia dentro dele. O vazio, o medo, o terror das pancadas tudo tinha fugido, só os olhos esquivados do companheiro 
lhe iluminavam o caminho" (VIEIRA, 1985, p. 152); ou Lucas Matesso, de "O fato completo de Lucas Matesso", que mesmo sob tortura não entrega o nome que guardava em segredo: "a dor era muita a pisar-lhe em todo o corpo, três meses de castigo e fome, pancadas e conversas, tinham-lhe custado aguentar ficar calado com o nome de Domingos" (VIEIRA, 1985, p. 137).

Outras narrativas do livro, entretanto, representam a morte como morte física, o ciclo da morte que consagra a ascensão do herói para o plano da eternidade. Do mesmo modo que os heróis clássicos, depois de mortos, passavam a ocupar um lugar de destaque nas comunidades, algumas das narrativas de Vidas Novas apresentam a projeção da jornada do herói no futuro da comunidade. Como a trajetória individual que se conecta com o devir coletivo passa para o domínio do mito que sobrevive para além do tempo da vida humana: "Aprendam as estórias bonitas dos animais da nossa terra, mas não esqueçam, no vosso coração, esse nome de Cardoso Kamukolo!" (VIEIRA, 1985, p. 109). Ao projetar a entrada da estória para o domínio do mito, Luandino descreve um tempo para além do qual pode ter experiência e narra um futuro que é bom ejusto graças ao fim da guerra e à vitória dos nacionalistas angolanos: "Depois, nessa voz dele cheia de vida, nos olhos que viram os maus tempos e nas mãos que ajudaram a fazer a vida boa desses dias, os monas vão ver como vavô ou papá pode mesmo saber contar essas coisas" (VIEIRA, 1985, p. 95).

O conceito de real representado em Vidas Novas ultrapassa, assim, o domínio do que se poderia conhecer, transformandose em algo também capaz de abranger expectativas de futuro concebíveis a partir da mediação da experiência estética. Mais ainda, essa estratégia realista de escrita se relaciona intimamente com uma autoconsciência histórica de sua época como tempo de transição entre um passado ainda não completamente em ruínas e um novo tempo que já se anunciava. Nesse sentido, a escrita de Luandino Vieira parece empenhada em produzir um movimento de aceleração do tempo. Seria a partir de uma tomada de consciência que as mais diversas pessoas poderiam se engajar no processo revolucionário e concretizar, por fim, o alvorecer do novo tempo que se projetava. Caberia então aos artistas a produção dos instrumentos culturais capazes de promover essa consciencialização, acelerando o tempo de transição entre o passado que definhava e o futuro que já nascia. O entendimento 
do tempo histórico se afasta, dessa maneira, tanto da ideia do tempo cíclico, que fundamentava o topos Historia Magistra Vitae, quanto do tempo como superação constante de si mesmo que inspirava as vanguardas do século XIX.

A noção do seu tempo como um tempo de transição está intimamente ligada ao conceito de revolução conforme se apresentava no século XX. A ideia de que o objetivo de uma revolução política seria a emancipação dos indivíduos e a transformação estrutural da sociedade só se tornou disponível no pensamento filosófico a partir da Revolução Francesa. Foi Marx, entretanto, quem posteriormente levou adiante a noção de coincidência entre revolução política e social, que inspirou a autoconsciência histórica partilhada por Luandino Vieira e outros artistas interessados na programática da revolução cultural durante sua contemporaneidade:

Ao cunhar a fórmula dualista - Toda revolução desfaz a velha sociedade; nesse sentido, ela é social; toda revolução derruba o velho poder; nesse sentido ela é política - o jovem Marx formulava também o princípio universal cuja concepção se tornara possível desde 1789 (KOSELLECK, 2006, p. 72).

As narrativas de Vidas Novas estão, dessa forma, filiadas ao entendimento do fluxo da história presente no momento de crítica da modernidade da segunda metade do século XX. O fim da Segunda Guerra Mundial com a derrota dos Nazifascismos produziu uma expectativa de independência dos antigos territórios coloniais europeus. A escrita romanesca, interessada em investigar as questões relativas à existência humana, passa a ser permeada pela maneira através da qual conceitos como história, real e revolução são transformados pelas condições específicas do espaço de experiência dessa época. $\mathrm{O}$ herói, em Luandino Vieira, recupera as funções e características do mito do herói clássico, adequando-as a uma estratégia literária inspirada pelos programas marxistas para uma revolução universal baseada na impressão da consciência revolucionária no próprio corpo das massas.

A partir dos personagens de Vidas Novas e suas jornadas de iniciação ou de ascensão, somos capazes de perceber como transformações em conceitos-chave para entender o espaço de experiência do mundo foram representadas no campo da cultura, emergindo para a superfície das palavras e para as 
formas narrativas. O herói, secularizado pela estratégia realista, manteve o seu aspecto etimológico de "guardião, defensor, o que nasceu para servir" (BRANDÃO, 2002, p. 15). Entretanto, em Vidas Novas, esses conceitos são redimensionados pela convicção de que todos os problemas locais se conectam a uma teia global de relações. Trajetórias individuais que se ligam a causas coletivas da mesma maneira que causas locais se entrelaçam a uma conjuntura geopolítica mundial.

\section{Agradecimentos}

Agradeço à FAPERJ e à UFF pelo financiamento do presente artigo.

\section{REFERÊNCIAS}

BRANDÃO, J. de S. Mitologia Grega. Vol. 3. Petrópolis: Vozes, 2002. CAMPBELL, J. O herói de mil faces, 10 ed. São Paulo: Cultrix/ Pensamento, 1997.

KOSELLECK, R. Futuro Passado: contribuição à semântica dos tempos históricos. Rio de Janeiro: Editora PUC Rio, 2006.

KUNDERA, M. A arte do romance. São Paulo: Companhia das Letras, 2009.

LOSA, M. O herói coletivo: um aspecto da estratégia romântica do romance neorrealista. Vértice, $n^{\circ}$ 21, Dez., 1989.

PIRES, T. de A. L. C. Representações bélicas na Arte Augustana e a consolidação da identidade imperial romana. Revista História e Cultura, Franca-SP, v.2, n.3 (Especial), 2013.

RODRIGUES, A. A Eneida virgiliana, entre a vivência e a narração. In: VIRGÍLIO. Eneida. São Paulo: Editora Unicamp, 2005.

VIEIRA, L. Vidas Novas. Havana: Ediciones Cubanas, 1985.

VIRGÍLIO. Eneida. São Paulo: Unicamp, 2005. 


\section{Abstract \\ The heroic sense of life in Vidas Novas, from Luandino Vieira}

The hero and his adventure constitute one of the most revisited topics of the narrative tradition, going back to the classic antiquity. Based on different figurations of the hero we can perceive specific aspects of the societies where they were produced. How they understood the historical time, defined concepts like justice, value or represented conflict. The hero myth proclaims itself as an exemplary narrative, revealing the moral content of a specific community and conferring origin, value and purpose to the most diverse cultural elements. Thus, the focalization on the myth of the hero allows us to grasp the influences of the political field on the cultural domain. Furthermore, heroes institute new communities, found cities and new ways of inhabiting the space. Their stories alter the forms of understanding the experience of the present, as well as the expectations for the future, shedding light on the influences of the field of aesthetic representation on the production of logical forms. The aim of this article is to compare some of the main aspects of the hero myth in its classical typology with the figurations of the hero in Vidas Novas (New Lifes), from Luandino Vieira. Based on those differences and similarities, this paper intends to discuss how specific ways of understanding human existence in the world emerge to the surface of the words and narrative forms.

Keywords: Hero; Historical Self-conscience; Luandino Vieira; New Lifes; Realism. 